\title{
A Dialogue on Quality and Patient Safety with Maureen Bisognano
}

A dinner for healthcare leaders at the 6th National Conference on Quality featured a conversation with Maureen Bisognano, Executive VP and $\mathrm{COO}$ of the Institute for Healthcare Improvement (IHI). IHI is a leading source of innovation in the improvement of healthcare. The conversation was facilitated by G. Ross Baker, professor in the Department of Health Policy, Management and Evaluation at the University of Toronto.

Following are highlights from the rich dialogue that evening.

Ross - Maureen, it is really exciting to have you with us in Toronto. I would like to pick up on a few themes from this conference. One of them is this idea of "pursuing perfection."* Many people in Canadian healthcare, would disagree that it's possible to take an organization and not just improve selected parts of it but move all of it towards a new, higher standard of performance. What is different in these organizations that you've been involved with?

Maureen - One of the big things that we have learned is the role of leadership. We used to think that we could get a team to decrease medication errors, but we can't get to that kind of improvement without a connection between leadership and the team. If you spent a day with one of the CEOs from a "pursuing perfection" organization, you would find they are asking different questions; they have different skills. What they found is that when they were educated in healthcare administration, they learned a set of skills; there was a framework, a curriculum and a set of core competencies. Improving care

\footnotetext{
* Pursuing Perfection is a Robert Wood Johnson Foundation project engaging organizations from the US and Europe in improving care across the range of facilities.
} 
wasn't one of them. I teach at Harvard. The amount of time dedicated to teaching Harvard medical students to improve care is pitiful. I was a nurse before I did any of this. We didn't learn improvement. So what we're learning now is that there is a different curriculum that leaders need to learn and we call it "the leadership of improvement."

When you talk to a CEO who hasn't learned improvement, they think about finance in a traditional way. They typically don't see waste, since they don't learn about it in their curriculum. Don Berwick and I have spent the last several years with CEOs from other industries, like Jack Welch from GE, Ralph Lawson from Johnson \& Johnson and Livio DeSimone from 3M. These CEOs have a leadership-forimprovement mindset. So while they know all the traditional ways to think about finance and they also know the connection between quality and cost. They know that sometimes improving quality costs money and that many times improving quality saves money. They even have little dials in their head; they know how much money they need to save in the next year so that they can reinvest that money into quality. We find many healthcare leaders don't think that way.

A second thing that we are noticing is that senior teams in "pursuing perfection" organizations are stronger. There has been international research done that shows that the most substantial impediment to transforming an organization is disharmony on the senior team. One or two members of the senior team don't buy in to the need for improve- ment. And we've tolerated it. We would not tolerate a VP of operations who [said], "I just don't believe in finance." And yet, we allow senior leaders to sit at the table and say they are not into the "quality thing." What we're finding is that if you have disharmony on the senior team, the CEO is spending more time trying to resolve disputes between senior team members than on improvement. Senior leaders who understand quality improvement are different, and their senior teams are different.

\section{Audience Question - How do you get senior teams to start working together to get buy-in?}

Maureen - We are explaining to CEOs that we see this as a barrier. We are saying if you have a vision of transformation, like pursuing perfection, we know that this is going to hold you back. They can see it themselves when they start becoming more conscious of the issue. They see how much time they are investing in the arbitration process. They have become very conscious of their own processes and the waste in these processes. They are trying to drive a different view of cost and how they interact with the system.

\section{Audience Question - There is a great deal of resistance from clinical staff to change. How do we address this resistance?}

Maureen - I think you're raising a really important point. We know there are going to be CEOs and frontline staff who feel comfortable improving 
work. But we also know there is a lot of discontent and the gaps are very real. So Don and I have created an agenda for change with five goals: no needless deaths, no needless pain, no helplessness, no delays and no waste.

When we put that agenda up, it's amazing what happens to leaders. The president of the American Medical Association came to us and said that is the agenda that we need to work on together. Dennis O'Leary brought the whole Joint Commission senior leadership team to the office for two days. The American Hospital Association is saying, "can we work on this project together?" So what we are doing is creating a national agenda. Now, what does "no needless deaths" mean? "No needless deaths" means we have hospitals in the United States now that have not had a case of ventilator-acquired pneumonia (VAP) in eight months. Before we started the ventilator project, VAP was a "complication." I worked in an ICU and the attitudes of doctors and nurses were, "Oh that's too bad it happened." It wasn't something that they felt they controlled; it was something that just happened some percentage of the time. And it was unfortunate that people died from it.

We started a project with a group of ICUs in the country and now we have about 40 or 50 hospitals that have virtually eliminated VAP. In these ICUs the measurement system doesn't count cases with VAP, instead it counts days between VAPs. At Dominican Hospital in Santa Cruz, California, after eight months a patient acquired a VAP and the doctors and nurses cried. They called it a failure. That's transformation, to have people classify a complication as a failure.

How do you eliminate VAP? It's not rocket science. There are four things you need to do and you need to do them all the time to every patient. You need to keep the head of the bed up 30 degrees; you need to do DVT prevention; you need to prevent peptic ulcer disease; and you need to do sedation vacations. If you can do those things, you can eliminate VAP. I think it's the power of getting these bundles of changes into the hands of the frontline staff. It's needless when somebody dies of a ventilator-acquired pneumonia and that's what we're fighting against.

Ross - Maureen, you clearly have [a] spread strategy that deals with those improvements. Could you talk a little bit about that?

Maureen - We have developed a methodology for spread. The issues preventing spread of new ideas are partly technical and partly leadership, and you have to address both components.

Let me describe what the technical side might look like. There are a number of different models, but I 
will pick one to share with you from the University of Pittsburgh Medical Center (UPMC) at Shadyside. Every summer, their census drops and they close a unit which they make the innovation unit. They then make a list of all the issues that are driving the doctors, nurses and patients crazy. They have a computer randomly pick a head nurse, nurses and nursing assistants needed to staff the unit. They spend a week without any patients in the unit prioritizing which hassles they are going to work on and how they are going to solve the problem. For example, one thing they looked at was ER flow.

They analyzed the problems when a doctor says patients have to be admitted and the nurses on the floor fend them off. [They] call up and say "we have a patient for you," and they start in with "we're having a code" or "we're at change of shift" or "we're short-staffed" or "someone's infected, we have to move the patient to a different room." They fend off as long as they can, because if they fend off well, the patient will go to another unit and they reduce their work.

To address this problem, they created a role, called the Admission Nurse. This nurse hangs around in the emergency department and when an admission comes in, they get everything done; they do the care plan; they get the patient ready; then they bring the patient up to the floor and introduce them to the staff and place them into a bed. There is no bolus of additional work. They slide into the regular schedule. So, UPMC decides they are going to try this. They go through three weeks of trials, and get the innovation down pat. Then for spread, they close down that innovation unit for a week and write up the policies and procedures. Then, they go to every single nursing unit; this is the staff, not an innovation team; this is frontline staff. That's a spread strategy. It's works because you map it out; you say, "Who am I going to hit next?" You tell them you're coming; you create the infrastructure, create the learning tools and you go ahead and work on it.

Then there is the leadership piece. None of this will happen without leaders who insist on the highest level of performance. The CEO must look at performance variation across the organization and says, if we know how to do it well here, why would we accept anything less? When we went to visit Jack Welch, he had a piece of paper with all his companies listed down one side and all the performance variables listed across the top, and he would sit with all the presidents of the companies and run his finger across the page until he got to the best performance, he would circle that number and say, "You get a halo." Then he would run his finger across until he found the worst performance and he would put a square around it and say, "You get a tomb- 
stone." He would then tell the person with the tombstone to visit the person with the halo and let them know they had one month to become that good. If you have the intellectual capacity within your organization, there is an obligation to be that good everywhere.

Ross - Maureen, I have to follow up on your discussion of flow because right now there are waiting lists for many services in Canada. Thinking about flow is another way to restructure this problem. So, how do we move to this idea of flow? What does it actually look like to start work on flow?

Maureen - These problems are solvable by understanding the dynamics of the problem from an engineering point of view and seeing where the bottlenecks are. In some cities, that used to have hundreds of hours a week on ambulance diversions, there have been eliminated because they've eliminated backups in the ER by smoothing out OR schedules.

What you need is a team looking at the whole system. If you have an ER problem and patients are complaining about waiting, you cannot solve it by bringing together a team of ER people, they can't get there. It's a system problem. One simple example is we've found dramatic improvements in flow throughout the whole system by scheduling discharges like you schedule admissions. The patient picks the time, they schedule the appointment and then all the processes of care are orchestrated to come together at that time, and the patient goes home.

We're seeing dramatic improvements in cancer care in the UK with no more cancer beds or operating rooms because they are smoothing out flow and using resources better. I would recommend that you don't invest a lot of time in making waiting lists better because all that does is expend a tremendous amount of resources in managing the lists. You're taking care of the waiting lists when you could be taking care of patients. We can figure out how to smooth out the flow and it's being done in hospitals all over the UK and US. We've seen hospitals that have increased their volume, increased their throughput and increased their caseload with no additional capital capacity. It happens when the leaders of the hospital get curious and they really start studying flow. When the leaders get excited about the concepts and they start digging, we start to see a lot happen.

Ross - Maureen, it has been a pleasure to have this conversation and listen to your experiences. Thank you for being here with us tonight.

Maureen - Thank you. 